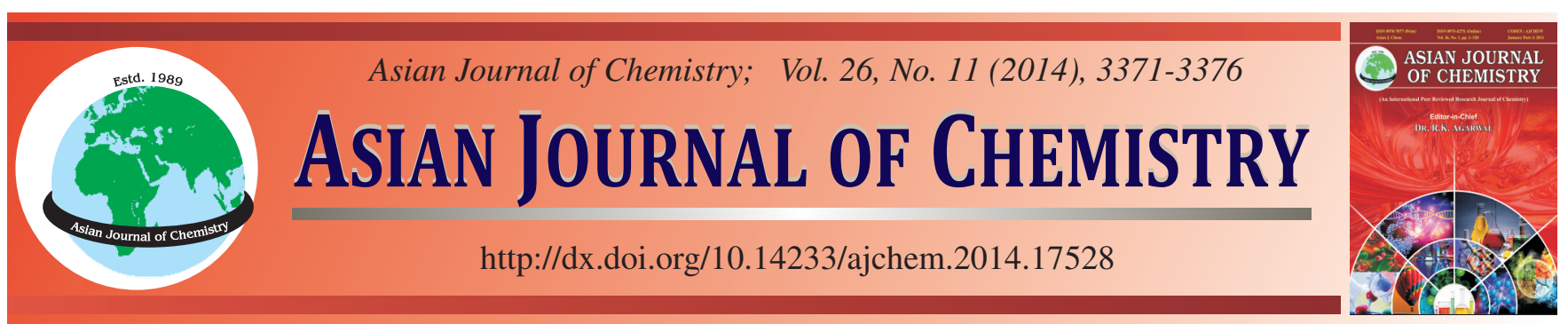

\title{
Study on Solution Space for Visual Positioning Algorithm from Linear Features
}

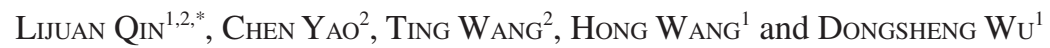

${ }^{1}$ School of Information Science and Engineering, Shenyang Ligong University, Shenyang, P.R. China

${ }^{2}$ State Key Laboratory of Robotics, Shenyang Institute of Automation, Chinese Academy of Science, Shenyang, P.R. China

*Corresponding author: Fax: +86 24 24682012; Tel: +86 15142539968; E-mail: qinlijuan06@163.com

\begin{abstract}
New solution method is presented for vision positioning method from straight lines intersecting at two spatial points. The solution method has fast calculation and can guarantee the uniqueness for solution. Application of this method is to satisfy precondition of monotony. This paper studies the geometry of space and gives sufficient proof of the monotonic the algorithm satisfies in the geometric range. In the spatial distribution of linear feature, geometric space can guarantee the convergence of the method. Thus, it can provide sufficient theoretical basis for the practical application of designed iterative method. Meanwhile, it can ensure the calculation speed and the uniqueness of solving methods. Simulation results show that iterative method can converge to right solution in the geometric space and has rapid iteration speed.
\end{abstract}

Keywords: Visual positioning, Solution space, Linear feature.

\section{INTRODUCTION}

In computer vision, visual positioning is to estimate three dimensional attitude of an object with respect to camera. It has become a hot research topic for vision positioning based on line features for computer vision communities since 2002. Visual positioning algorithm from single camera has wide varieties of applications, such as obstacle avoidance, industrial production and robot self-positioning ${ }^{1-4}$.

For vision positioning with line correspondences, minimum of three straight lines is required to solve the problem of pose estimating, where not two of which are parallel. Then three lines can produce three non-linear equations, so the vision positioning question is converted into solving a non-linear equations set. Currently, approaches to solve this question fall into two classes: closed-form methods and iterative methods ${ }^{5}$.

For iterative algorithms, Yuan ${ }^{6}$ has used Newton's method to determine the position of $3 \mathrm{D}$ object with respect to a camera. Liu et al. ${ }^{7}$ have examined alternative iterative methods to solve the vision pose. Phong et al..$^{5}$ used trust region optimization algorithm to solve orientation and location in 1995. Christy and Horaud ${ }^{8}$ heve calculated viewing parameters from iterative method, which started with a solution near to true solution. Iterative approaches have two shortcomings, which need a good initial estimation of the true solution and be time-consuming.
A new method for estimating object vision pose for three non-coplanar lines which intersect at two points has been proposed by Qin and Zhu'. We have presented a new iterative method which is based on the geometry and step acceleration method for the solution of this method. This method gives insight into the geometric characteristics of the problem. The search process satisfies convergence characteristic, so the solution method can avoid be trapped in local minima. Meanwhile, the solution method is free of choosing original estimation value and it can find the true value ever if the initial estimation is far from true value.

The premise for running of our iterative method is existing convergence region. For this reason, we will give detailed proof for convergence of solution space. The value of the proof is to provide the theoretical basis for iterative solution method and guide the application of the solution method. We have found one region where iterative method satisfies converge in paper ${ }^{10-12}$. In recent research work, we have found another region where this iterative method can also satisfy convergence. The work of this paper is to present and proof this region.

Vision positioning method from three lines: We consider pin-hole camera model. The intrinsic camera parameters are assumed to be known. Fig. 1 is perspective projection of three general lines intersecting at two points in monocular vision. 


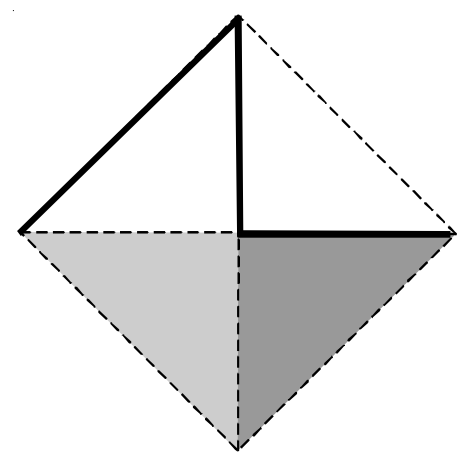

Fig. 1. Visual positioning model for space lines intersecting at two points

Line $L_{i}$, image line $l_{i}$ and the origin of the camera frame are constrained to lie in the same plane as shown in Fig. 2 by perspective projection model. This plane is called the explanation plane. We know model lines satisfy conditions which are $\left|\mathrm{p}_{2} \mathrm{p}_{3}\right|=\mathrm{a}$, angle between line $\mathrm{L}_{1}$ and line $\mathrm{L}_{2}$ is $\alpha$, angle between line $\mathrm{L}_{3}$ and line $\mathrm{L}_{2}$ is $\beta$ and angle between line $\mathrm{L}_{1}$ and line $\mathrm{L}_{3}$ is $\gamma$.

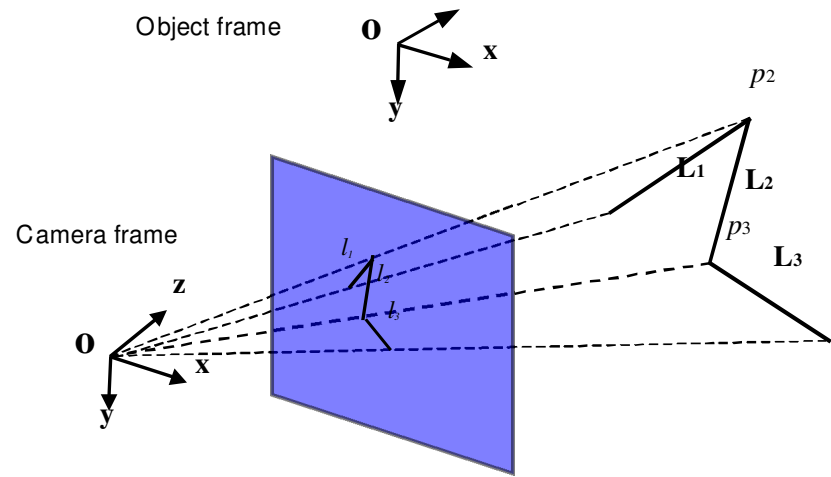

Fig. 2. Perspective projection for three line features intersecting at two points in monocular vision

Vector $\mathrm{N}_{\mathrm{i}}=\left(\mathrm{N}_{\mathrm{i} 1}, \mathrm{~N}_{\mathrm{i} 2}, \mathrm{~N}_{\mathrm{i} 3}\right)^{\mathrm{T}}$ normal to the explanation plane can be computed as the cross product of vector ot and vector $\mathrm{v}_{\mathrm{t}}$, it can be get that ot $\mathrm{t}_{\mathrm{i}}=\left(\mathrm{x}_{\mathrm{i}}, \mathrm{y}_{\mathrm{i}}, \mathrm{f}\right)^{\mathrm{T}}, \mathrm{v}_{\mathrm{i}}=\left(-\mathrm{b}_{\mathrm{i}}, \mathrm{a}_{\mathrm{i}}, 0\right)^{\mathrm{T}}$. Then $\mathrm{N}_{\mathrm{i}}=\mathrm{v}_{\mathrm{i}}$ $\times \mathrm{ot}_{\mathrm{i}}=\left(\mathrm{a}_{\mathrm{i}} \mathrm{f}, \mathrm{f}_{\mathrm{i}} \mathrm{f}, \mathrm{c}_{\mathrm{i}}\right)^{\mathrm{T}}$ can be computed.

Because line $\mathrm{L}_{1}$ lies in the interpretation plane formed by the image line $l_{1}$ and the optical center, the angle between line $L_{1}$ and line $L_{2}$ is $\alpha$ and the norm of the vectors of line $L_{1}$ is unit, we can obtain equation as following:

$$
\begin{aligned}
\mathrm{A}_{1} \mathrm{~N}_{11}+\mathrm{B}_{1} \mathrm{~N}_{12}+\mathrm{C}_{1} \mathrm{~N}_{13} & =0, \mathrm{~A}_{1} \mathrm{~A}_{2}+\mathrm{B}_{1} \mathrm{~B}_{2}+\mathrm{C}_{1} \mathrm{C}_{2} \\
= & \cos \alpha, \mathrm{A}_{1}^{2}+\mathrm{B}_{1}^{2}+\mathrm{C}_{1}^{2}=1
\end{aligned}
$$

For line $\mathrm{L}_{3}$, because line $\mathrm{L}_{3}$ lies in the interpretation plane formed by the image line $l_{3}$ and the optical center, the angle between line $L_{3}$ and line $L_{2}$ is $\beta$ and meanwhile norm of the vectors of line $\mathrm{L}_{3}$ is unit, we can have equation as following:

$$
\begin{aligned}
\mathrm{A}_{3} \mathrm{~N}_{13}+\mathrm{B}_{3} \mathrm{~N}_{32}+\mathrm{C}_{3} \mathrm{~N}_{33} & =0, \mathrm{~A}_{3} \mathrm{~A}_{2}+\mathrm{B}_{3} \mathrm{~B}_{2}+\mathrm{C}_{3} \mathrm{C}_{2} \\
& =\cos \beta, \mathrm{A}_{3}^{2}+\mathrm{B}_{3}^{2}+\mathrm{C}_{3}^{2}=1
\end{aligned}
$$

From condition that the angle between line $\mathrm{L}_{1}$ and line $\mathrm{L}_{3}$ is $\gamma$, we get:

$$
\mathrm{A}_{1} \mathrm{~A}_{3}+\mathrm{B}_{1} \mathrm{~B}_{3}+\mathrm{C}_{1} \mathrm{C}_{3}=\cos \gamma
$$

Substituting eqns. 1 and 2 into 3 , we can obtain a new expression.
Direction vectors of line $L_{2}$ can be expressed by points $p_{2}$ and $\mathrm{p}_{3}$ :

$$
\begin{gathered}
\mathrm{L}_{2}=\left(\mathrm{A}_{2}, \mathrm{~B}_{2}, \mathrm{C}_{2}\right)^{\mathrm{T}}=\left(\mathrm{k}_{3} \mathrm{x}_{3}-\mathrm{k}_{2} \mathrm{x}_{2}, \mathrm{k}_{3} \mathrm{y}_{3}-\mathrm{k}_{2} \mathrm{y}_{2}, \mathrm{k}_{3} \mathrm{z}_{3}\right. \\
\left.-\mathrm{k}_{2} \mathrm{z}_{2}\right)^{\mathrm{T}}
\end{gathered}
$$

Substitute eqn. 4 into 3 , equation about $\mathrm{k}_{2}$ and $\mathrm{k}_{3}$ can be obtained.

From condition $\left|\mathrm{p}_{2} \mathrm{p}_{3}\right|=\mathrm{a}$, we get:

$$
\left(\mathrm{k}_{3} \mathrm{z}_{3}-\mathrm{k}_{2} \mathrm{z}_{2}\right)^{2}+\left(\mathrm{k}_{3} \mathrm{y}_{3}-\mathrm{k}_{2} \mathrm{y}_{2}\right)^{2}+\left(\mathrm{k}_{3} \mathrm{x}_{3}-\mathrm{k}_{2} \mathrm{x}_{2}\right)^{2}=\mathrm{a}^{2}(5)
$$

So far we get two equations about two unknowns. If we substitute one into another, we can have one new expression. We assume the new equation is $\mathrm{f}\left(\mathrm{k}_{2}\right)=0$. If we obtain the value of $\mathrm{k}_{2}$, thus $\mathrm{k}_{3}, \mathrm{~A}_{1}, \mathrm{~B}_{1}, \mathrm{C}_{1}, \mathrm{~A}_{2}, \mathrm{~B}_{2}, \mathrm{C}_{2}, \mathrm{~A}_{3}, \mathrm{~B}_{3}, \mathrm{C}_{3}$ can be determined from corresponding equations, then the coordinates of $\mathrm{p}_{2}$ and $\mathrm{p}_{3}$ and the director vectors of line $\mathrm{L}_{1}, \mathrm{~L}_{2}, \mathrm{~L}_{3}$ in camera frame can be computed. We propose one solution method which is based on geometry and step acceleration method to solute $\mathrm{k}_{2}$.

Solution approach: From above analysis, we obtain one expression $\mathrm{F}$ which is in terms of one variant $\mathrm{k}_{2}$ and this expression is complex to solve. To solve this problem, we present a new method to compute based on geometry and step acceleration method.

The optical center is supposed to O. $S_{1}$ is explanation plane formed by image line $\mathrm{l}_{\mathrm{i}}$ and $\mathrm{O}, \mathrm{S}_{2}$ is plane formed by image lineand. $S_{3}$ is plane formed by image line $l_{3}$ and $O . J_{3}$ is the intersection line which is formed by the explanation plane $S_{1}$ and the explanation plane $S_{2} . J_{4}$ is the intersection line formed by plane $S_{2}$ and $S_{3}$ (Fig. 3).

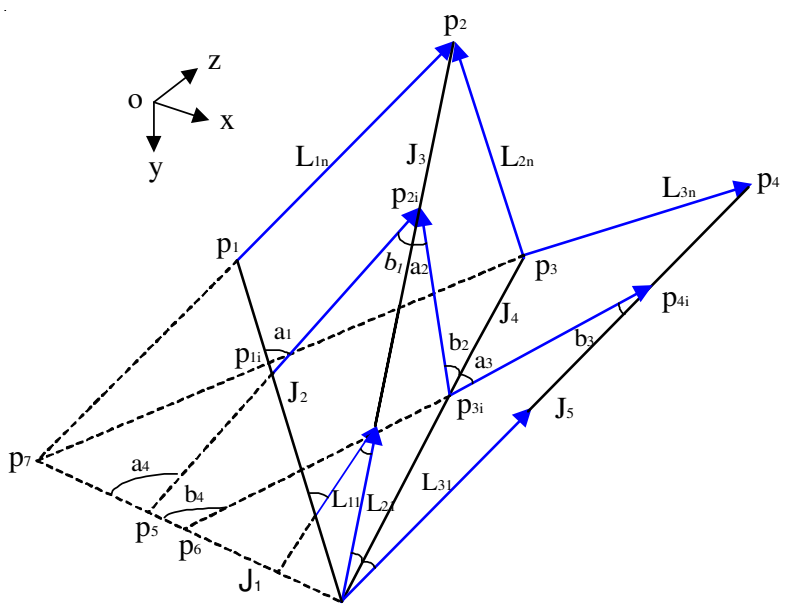

Fig. 3. Iterative solution process

Correct value of $\mathrm{k}_{2}$ is searched based on geometry and step acceleration method (Fig. 3), we select a point $\mathrm{p}_{2 \mathrm{i}}$ on line $\mathrm{J}_{3}$ which is near the optical center firstly. Second, we continue to search point $p_{3 i}$ at a distance of a from point $p_{2 i}$ on line $J_{4}$. Line $\mathrm{L}_{2 \mathrm{i}}$ is formed by point $\mathrm{p}_{2 \mathrm{i}}$ and point $\mathrm{p}_{3 \mathrm{i}}$. Third, we find a line $\mathrm{L}_{1 \mathrm{i}}$ on explanation plane $S_{1}$ which forms an angle of a with line $\mathrm{L}_{2 \mathrm{i}}$. Fourth, we find the line $\mathrm{L}_{3 \mathrm{i}}$ on explanation plane $\mathrm{S}_{3}$ which makes an angle of $\beta$ with line $L_{2 i}$. Angle $\gamma_{i}$ is formed by line $\mathrm{L}_{1 \mathrm{i}}$ and line $\mathrm{L}_{3 \mathrm{i}}$. Angle between line $\mathrm{L}_{1 \mathrm{i}}$ and line $\mathrm{L}_{3 \mathrm{i}}$ becomes larger with the increase of the distance between point $\mathrm{p}_{2 \mathrm{i}}$ and the optical center of camera. Point $\mathrm{p}_{2 \mathrm{i}}$ and three lines $\mathrm{L}_{1 \mathrm{i}}, \mathrm{L}_{2 \mathrm{i}}$, 
$\mathrm{L}_{3 \mathrm{i}}$ reach the right position when the angle satisfies the known value $\gamma$. Then the whole iterative process finishes.

Solution space for visual positioning method and proof: (Fig. 3) we do some assumption. The angle between line $\mathrm{L}_{1}$ and line $J_{2}$ is $a_{1}$, angle between line $L_{1}$ and line $J_{3}$ is $b_{1}$ and angle between line $L_{2}$ and line $J_{3}$ is $a_{2}$. Angle between line $L_{2}$ and line $\mathrm{J}_{4}$ is $\mathrm{b}_{2}$, angle between line $\mathrm{L}_{3}$ and line $\mathrm{J}_{4}$ is $\mathrm{a}_{3}$ and angle between line $L_{3}$ and line $J_{5}$ is $b_{3}$. It is assumed that angle between line $L_{1}$ and line $J_{1}$ is $a_{4}$, the angle between line $L_{3}$ and line $J_{1}$ is $b_{4}$. The angle between explain plane $S_{1}$ and $S_{2}$ is $\varphi_{1}$, the angle between explain plane $S_{2}$ and $S_{3}$ is $\varphi_{2}$ and the angle between plane $S_{1}$ and plane $S_{3}$ is $\varphi_{3}$. At regions as following, the iterative method satisfies convergence and can find the right solution.

Solution space for visual positioning method:

$$
\begin{aligned}
(1) \cos \left(\varphi_{1}\right)>0,0<\mathrm{a}_{2}<\frac{\pi}{2}, \pi<\mathrm{b}_{1} & <\frac{3 \pi}{2}, \frac{3 \pi}{2}<\mathrm{b}_{1}+\gamma_{1}<\frac{5 \pi}{2} \\
(2) \frac{\pi}{2}<\varphi_{2}<\pi, 0<\mathrm{a}_{3} \frac{\pi}{2}, 0 & <\mathrm{b}_{2}<\frac{\pi}{2}, \frac{\pi}{2}<\mathrm{a}_{3} \\
& +\arctan \left(\frac{\cot \left(\mathrm{b}_{2}\right)}{\cos \left(\varphi_{2}\right)}\right)<\frac{3 \pi}{2}
\end{aligned}
$$

(3) $0<\varphi_{3}<\frac{\pi}{2}, 0<\mathrm{a}_{4}<\frac{\pi}{2}, 0<\mathrm{b}_{4}<\frac{\pi}{2}, \tan \left(\mathrm{a}_{4}\right) \cot \left(\mathrm{b}_{4}\right)>\frac{1}{\cos \left(\varphi_{3}\right)}$

Three conditions (1) (2) (3) are simultaneously satisfied.

Lemma 1: (Fig. 4) with the increase of variable $\mathrm{k}_{2}$, the angle $b_{1}$ will increase correspondingly in the case $\cos \left(\varphi_{1}\right)>$ $0,0<\mathrm{a}_{2}<\pi / 2, \pi<\mathrm{b}_{1}<3 \pi / 2,3 \pi / 2<\mathrm{b}_{1}+\gamma_{1}<5 \pi / 2$.

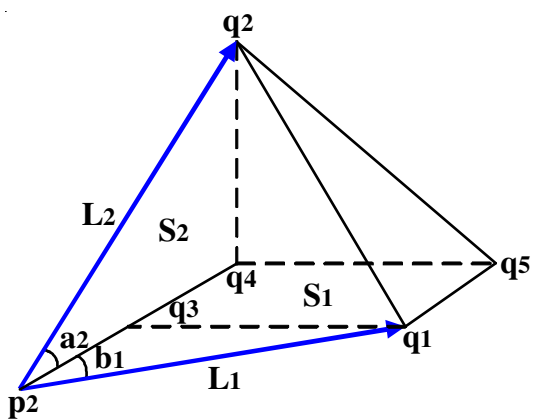

Fig. 4. Change trend analysis for line $\mathrm{L}_{1}$ with the development of $\mathrm{k}_{2}$

Proof: As shown in Fig. 3, it is obvious to see that as independent variable $\mathrm{k}_{2}$ increase, angle $\mathrm{a}_{2}$ and angle $\mathrm{b}_{2}$ will increase correspondingly.

Fig. 4, the length of line segment $\mathrm{p}_{2} \mathrm{q}_{2}$ and $\mathrm{p}_{2} \mathrm{q}_{1}$ are assumed to be one and angle $\varphi_{1}$ is invariant during iterative process. It is supposed to drop perpendicular line from point $\mathrm{q}_{1}$ to line $\mathrm{J}_{3}$ and intersect $\mathrm{J}_{3}$ at $\mathrm{q}_{3}$. Dropping perpendicular line from point $\mathrm{q}_{2}$ to line $\mathrm{j}_{3}$ and intersecting $\mathrm{j}_{3}$ at $\mathrm{q}_{4}$. Drawing line $\mathrm{q}_{4} \mathrm{q}_{5}$ parallel to line $\mathrm{q}_{1} \mathrm{q}_{3}$ from point $\mathrm{q}_{4}$. Furthermore, length of $\mathrm{q}_{1} \mathrm{q}_{3}$ is equal to length of $\mathrm{q}_{4} \mathrm{q}_{5}$. Connecting point $\mathrm{q}_{1}$ with point $\mathrm{q}_{2}$, point $\mathrm{q}_{1}$ with point $\mathrm{q}_{5}$ and point $\mathrm{q}_{2}$ with point $\mathrm{q}_{5}$.

$$
\begin{aligned}
& \text { In, } \begin{aligned}
& \Delta \mathrm{q}_{2} \mathrm{p}_{2} \mathrm{q}_{4}, \\
& \mathrm{p}_{2} \mathrm{q}_{4}=\mathrm{p}_{2} \mathrm{q}_{2} \cos \left(\mathrm{a}_{2}\right)=\cos \left(\mathrm{a}_{2}\right), \mathrm{q}_{2} \mathrm{q}_{4}=\mathrm{p}_{2} \mathrm{q}_{2} \sin \left(\mathrm{a}_{2}\right) \\
&=\sin \left(\mathrm{a}_{2}\right)
\end{aligned}
\end{aligned}
$$

In, $\Delta \mathrm{q}_{1} \mathrm{p}_{2} \mathrm{q}_{3}$,

$\mathrm{p}_{2} \mathrm{q}_{3}=\mathrm{p}_{2} \mathrm{q}_{1} \cos \left(\mathrm{b}_{1}\right)=\cos \left(\mathrm{b}_{1}\right), \mathrm{q}_{2} \mathrm{q}_{3}=\mathrm{p}_{2} \mathrm{q}_{1} \sin \left(\mathrm{b}_{1}\right)=\sin \left(\mathrm{b}_{1}\right)$

Since $\mathrm{q}_{1} \mathrm{q}_{3} \perp \mathrm{J}_{3}, \mathrm{q}_{4} \mathrm{q}_{5} \perp \mathrm{J}_{3}, \mathrm{q}_{1} \mathrm{q}_{5} \| \mathrm{q}_{3} \mathrm{q}_{4}, \mathrm{q}_{1} \mathrm{q}_{5}=\mathrm{q}_{3} \mathrm{q}_{4}$, then $\mathrm{q}_{1} \mathrm{q}_{3} \mathrm{q}_{4} \mathrm{q}_{5}$ satisfies to be rectangle. It can be get as following:

Thus,

$$
\mathrm{q}_{1} \mathrm{q}_{5}=\mathrm{q}_{3} \mathrm{q}_{4}, \mathrm{q}_{4} \mathrm{q}_{5}=\mathrm{q}_{1} \mathrm{q}_{3}
$$

$$
\mathrm{q}_{1} \mathrm{q}_{5}=\mathrm{p}_{2} \mathrm{q}_{4}-\mathrm{p}_{2} \mathrm{q}_{3}=\cos \left(\mathrm{a}_{2}\right)-\cos \left(\mathrm{b}_{1}\right)
$$

In $\Delta \mathrm{q}_{2} \mathrm{q}_{4} \mathrm{q}_{5}, \mathrm{q}_{2} \mathrm{q}_{4} \perp \mathrm{J}_{3}$ and $\mathrm{q}_{4} \mathrm{q}_{5} \perp \mathrm{J}_{3}$, it is obvious to get:

$$
\angle \mathrm{q}_{2} \mathrm{q}_{4} \mathrm{q}_{5}=\varphi_{1}
$$

Application the law of cosines,

$$
\begin{gathered}
q_{2} q_{5}=\sqrt{q_{2} q_{4}^{2}+q_{4} q_{5}^{2}-2 q_{2} q_{4} q_{4} q_{5} \cos \left(\varphi_{1}\right)} \\
=\sqrt{\sin \left(a_{2}\right)^{2}+\sin \left(b_{1}\right)^{2}-2 \sin \left(a_{2}\right) \sin \left(b_{1}\right) \cos \left(\varphi_{1}\right)}
\end{gathered}
$$

Since $\quad \mathrm{q}_{3} \mathrm{q}_{4} \perp \mathrm{q}_{2} \mathrm{q}_{4}, \mathrm{q}_{3} \mathrm{q}_{4} \perp \mathrm{q}_{4} \mathrm{q}_{5}$, we have $\mathrm{q}_{3} \mathrm{q}_{5} \perp \Delta \mathrm{q}_{2} \mathrm{q}_{4} \mathrm{q}_{5}$. In the further step, we can obtain $\mathrm{q}_{3} \mathrm{q}_{4} \perp \mathrm{q}_{2} \mathrm{q}_{5}$. Since $\mathrm{q}_{1} \mathrm{q}_{5} \| \mathrm{q}_{3} \mathrm{q}_{4}, \mathrm{q}_{3} \mathrm{q}_{4} \perp \mathrm{q}_{2} \mathrm{q}_{5}$, we have $\mathrm{q}_{1} \mathrm{q}_{5} \perp \mathrm{q}_{2} \mathrm{q}_{5}$. Therefore, $\Delta \mathrm{q}_{1} \mathrm{q}_{2} \mathrm{q}_{5}$ is a right triangle.

It is satisfied in $\Delta \mathrm{q}_{1} \mathrm{q}_{2} \mathrm{q}_{5}$,

$$
\begin{gathered}
\mathrm{q}_{1} \mathrm{q}_{2}=\sqrt{\left(\mathrm{q}_{1} \mathrm{q}_{5}\right)^{2}+\left(\mathrm{q}_{2} \mathrm{q}_{5}\right)^{2}}= \\
\sqrt{2-2 \sin \left(\mathrm{a}_{2}\right) \sin \left(\mathrm{b}_{1}\right)-2 \cos \left(\mathrm{a}_{2}\right) \cos \left(\mathrm{b}_{1}\right) \cos \left(\varphi_{1}\right)}
\end{gathered}
$$

In, $\Delta \mathrm{q}_{2} \mathrm{p}_{2} \mathrm{q}_{1}$,

$$
\begin{aligned}
& \cos \angle \mathrm{q}_{2} \mathrm{p}_{2} \mathrm{q}_{1}=\frac{\mathrm{q}_{2} \mathrm{p}_{2}^{2}+\mathrm{q}_{1} \mathrm{p}_{2}^{2}-\mathrm{q}_{2} \mathrm{q}_{1}^{2}}{2 \mathrm{q}_{2} \mathrm{p}_{2} \mathrm{q}_{1} \mathrm{p}_{2}} \\
& =\cos \left(\mathrm{a}_{2}\right) \cos \left(\mathrm{b}_{1}\right) \cos \left(\varphi_{1}\right)+\sin \left(\mathrm{b}_{1}\right) \sin \left(\mathrm{a}_{2}\right)
\end{aligned}
$$

Cosine of the angle between line $\mathrm{L}_{1}$ and line $\mathrm{L}_{2}$ is assumed to satisfy:

$$
\mathrm{F}=\cos \left(\mathrm{a}_{2}\right) \cos \left(\mathrm{b}_{1}\right) \cos \left(\varphi_{1}\right)+\sin \left(\mathrm{b}_{1}\right) \sin \left(\mathrm{a}_{2}\right)
$$

Eqn. 14 can be expressed as following:

$$
\mathrm{F}=\sqrt{1-\left(\sin \left(\mathrm{a}_{2}\right)\right)^{2}\left(\sin \left(\varphi_{1}\right)\right)^{2}}\left(\sin \left(\mathrm{b}_{1}+\gamma_{1}\right)\right)
$$

where, $\gamma_{1}=\arctan \left(\frac{\cot \left(\mathrm{a}_{2}\right)}{\cos \left(\varphi_{1}\right)}\right)$.

As independent variable $\mathrm{k}_{2}$ increases, $\mathrm{a}_{2}$ will increase correspondingly in the iterative process. Then $\sqrt{1-\left(\sin \left(\mathrm{a}_{2}\right)\right)^{2}\left(\sin \left(\varphi_{1}\right)\right)^{2}}$ will decrease.

As independent variable $\mathrm{k}_{2}$ increases, $\mathrm{a}_{2}$ will increase correspondingly in the iterative process. Then $\cot \left(\mathrm{a}_{2}\right)$ will decrease. For $\cos \left(j_{1}\right)>0$ and $\gamma_{1}=\arctan \left(\frac{\cot \left(a_{2}\right)}{\cos \left(\varphi_{1}\right)}\right)$, then $g_{1}$ will decrease as independent variable $\mathrm{k}_{2}$ increases. Because $3 \pi / 2<b_{1}+\gamma_{1}<5 \pi / 2$, thus $\sin \left(b_{1}+\gamma_{1}\right)$ will decrease with $\gamma_{1}$ decreasing. 
Conclusion can be easily get that if function $\mathrm{F}=\sqrt{1-\left(\sin \left(\mathrm{a}_{2}\right)\right)^{2}\left(\sin \left(\varphi_{1}\right)\right)^{2}}\left(\sin \left(\mathrm{b}_{1}+\gamma_{1}\right)\right)$ should remain constant, then $\sin \left(b_{1}+\gamma_{1}\right)$ will decrease. Because $3 \pi / 2<b_{1}+$ $\gamma_{1}<5 \pi / 2$ and $\gamma_{1}$ decreases, thus $b_{1}$ will increase. Therefore, as independent variable $\mathrm{k}_{2}$ increases, then $\mathrm{b}_{1}$ will increase in the case $\cos \left(\varphi_{1}\right)>0,0<\mathrm{a}_{2}<\pi / 2, \pi<\mathrm{b}_{1}<3 \pi / 2,3 \pi / 2<\mathrm{b}_{1}+\gamma_{1}<$ $5 \pi / 2$. Q.E.D.

Lemma 2: Fig. 5, with the increase of independent variable $\mathrm{k}_{2}, \mathrm{a}_{3}$ should increase correspondingly in the case $\pi / 2$ $<\varphi_{2}<\pi, 0<\mathrm{a}_{3}<\pi / 2, \pi / 2<\mathrm{a}_{3}+\arctan \left(\frac{\cot \left(\mathrm{b}_{2}\right)}{\cos \left(\varphi_{2}\right)}\right)<\frac{3 \pi}{2}$.

Proof: Cosine of the angle between line $\mathrm{L}_{2}$ and line $\mathrm{L}_{3}$ is assumed to satisfy the following expression:

$$
\mathrm{F}=\cos \left(\mathrm{a}_{3}\right) \cos \left(\mathrm{b}_{2}\right) \cos \left(\varphi_{2}\right)+\sin \left(\mathrm{b}_{2}\right) \sin \left(\mathrm{a}_{3}\right)
$$

Eqn. 16 is arranged into:

$$
\mathrm{F}=\sqrt{1-\left(\sin \left(\mathrm{b}_{2}\right)\right)^{2}\left(\sin \left(\varphi_{2}\right)\right)^{2}}\left(\sin \left(\mathrm{a}_{3}+\gamma_{2}\right)\right)
$$

where, $\gamma_{2}=\arctan \left(\frac{\cot \left(b_{2}\right)}{\cos \left(\varphi_{2}\right)}\right)$.

With the increase for independent variable $\mathrm{k}_{2}, \mathrm{~b}_{2}$ will increase correspondingly in the iterative process, then $\sqrt{1-\left(\sin \left(b_{2}\right)\right)^{2}\left(\sin \left(\varphi_{2}\right)\right)^{2}}$ will decrease.

With the increase for independent variable $\mathrm{k}_{2}$ in the iterative process, $b_{2}$ will increase correspondingly, thus cot $\left(b_{2}\right)$ will decrease. For $\pi / 2<\varphi_{2}<\pi$, thus $\cos \left(\varphi_{2}\right)>0$. Because $\gamma_{2}=\arctan \left(\frac{\cot \left(b_{2}\right)}{\cos \left(\varphi_{2}\right)}\right)$, then $\gamma_{2}$ will decrease.

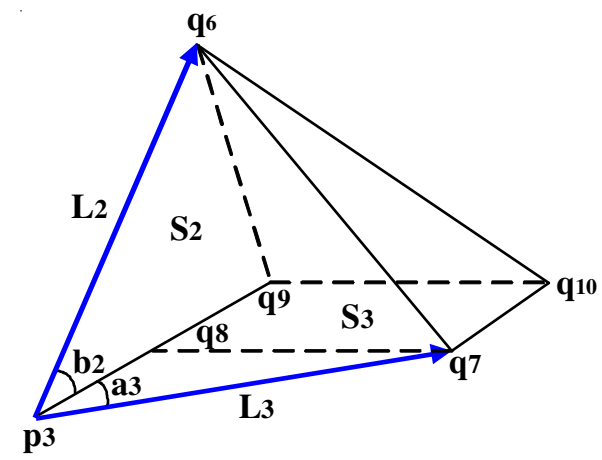

Fig. 5. Change trend analysis for line $\mathrm{L}_{3}$ with the development of $\mathrm{k}_{2}$

Since $\mathrm{p} / 2<\mathrm{a}_{3}+\arctan \left(\frac{\cot \left(\mathrm{b}_{2}\right)}{\cos \left(\varphi_{2}\right)}\right)<\frac{3 \pi}{2}$, then $\pi / 2<\mathrm{a}_{3}+$ $\mathrm{r}_{2}<3 \pi / 2$ and $\sin \left(\mathrm{a}_{3}+\gamma_{2}\right)$ will decrease with $\gamma_{2}$ increasing.

Function $\mathrm{F}=\sqrt{1-\left(\sin \left(\mathrm{b}_{2}\right)\right)^{2}\left(\sin \left(\varphi_{2}\right)\right)^{2}}\left(\sin \left(\mathrm{a}_{3}+\gamma_{2}\right)\right)$ should remain constant. As independent variable $\mathrm{k}_{2}$ increases, $\sqrt{1-\sin \left(b_{2}\right) \sin \left(\varphi_{2}\right)^{2}}$ will decrease, that is $\sin \left(a_{3}+\gamma_{2}\right)$ will increase.

It can be obtained that $\mathrm{a}_{3}$ will decrease because $\pi / 2<\mathrm{a}_{3}+$ $\mathrm{r}_{2}<3 \pi / 2$.
Therefore, with the increase of independent variable $\mathrm{k}_{2}$, $a_{3}$ will increase correspondingly in the case $\pi / 2<\varphi_{2}<\pi, 0<a_{3}$ $<\pi / 2,0<\mathrm{b}_{2}<\pi / 2, \pi / 2<\mathrm{a}_{3}+\arctan \left(\frac{\cot \left(\mathrm{b}_{2}\right)}{\cos \left(\varphi_{2}\right)}\right)<\frac{3 \pi}{2}$. Q.E.D.

Theorem: Fig. 6, with the increase of independent variable $k_{2}$, angle between line $L_{1}$ and line $L_{3}$ should increase correspondingly in the case $0<\varphi_{3}<\pi / 2,0<\mathrm{a}_{4}<\pi / 2,0<\mathrm{b}_{4}<$ $\pi / 2, \tan \left(\mathrm{a}_{4}\right) \cot \left(\mathrm{b}_{4}\right)>\frac{1}{\cos \left(\varphi_{3}\right)}$.

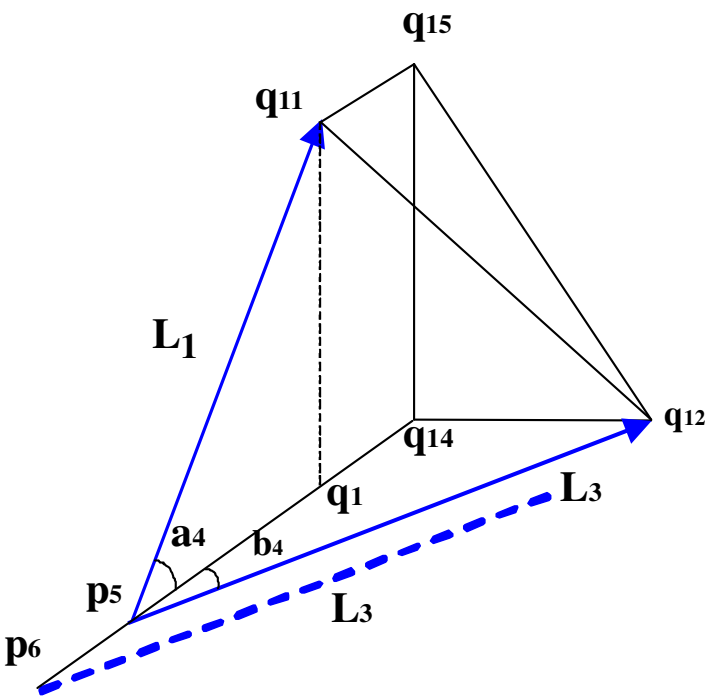

Fig. 6. Change trend analysis for angle between line $\mathrm{L}_{1}$ and line $\mathrm{L}_{3}$ with the development of $\mathrm{k}_{2}$

Proof: Cosine of the angle between line $\mathrm{L}_{1}$ and line $\mathrm{L}_{3}$ is assumed to satisfy:

$$
\mathrm{F}=\cos \left(\mathrm{a}_{4}\right) \cos \left(\mathrm{b}_{4}\right) \cos \left(\varphi_{3}\right)+\sin \left(\mathrm{b}_{4}\right) \sin \left(\mathrm{a}_{4}\right)
$$

Eqn. 18 is arranged into:

$$
\mathrm{F}=\sqrt{1-\left(\sin \left(\mathrm{a}_{4}\right)\right)^{2}\left(\sin \left(\varphi_{3}\right)\right)^{2}}\left(\sin \left(\mathrm{b}_{4}+\gamma_{3}\right)\right)
$$

where, $\gamma_{3}=\arctan \left(\frac{\cot \left(\mathrm{a}_{4}\right)}{\cos \left(\varphi_{3}\right)}\right)$.

Considering $\tan \left(\mathrm{b}_{4}\right) \cot \left(\mathrm{a}_{4}\right)>\frac{1}{\cos \left(\varphi_{3}\right)}$, we have $\frac{\cot \left(a_{4}\right)}{\cos \left(\varphi_{3}\right)}<\tan \left(\frac{\pi}{2}-b_{4}\right) \cdot$ Since $\tan \left(\gamma_{3}\right)=\frac{\cot \left(a_{4}\right)}{\cos \left(\varphi_{3}\right)}$, we have $\tan \left(\gamma_{3}\right)<\tan \left(\frac{\pi}{2}-b_{4}\right)$ and $0<b_{4}+\gamma_{3}<\pi / 2$.

As the same as proof process of Lemma 1 , it can be readily get that angle $b_{1}$ will increase correspondingly in the case cos $\left(\varphi_{1}\right)>0,0<\mathrm{a}_{2}<\pi / 2, \pi<\mathrm{b}_{1}<3 \pi / 2,3 \pi / 2<\mathrm{b}_{1}+\gamma_{1}<5 \pi / 2$ as independent variable $\mathrm{k}_{2}$ increases. It is considered that $\mathrm{a}_{4}=\mathrm{b}_{1}$ $+\angle \mathrm{p}_{2} \mathrm{Op}_{5}$ and $\angle \mathrm{p}_{3} \mathrm{Op}_{6}$ do not change in iterative process, thus it is easy to obtain angle $\mathrm{a}_{4}$ will increase correspondingly in this case as independent variableincreases. 
Therefore, $\sqrt{1-\left(\sin \left(a_{4}\right)\right)^{2}\left(\sin \left(\varphi_{3}\right)\right)^{2}}$ will decrease for increase of $\mathrm{a}_{4}$.

It can be obtained that cot $\left(a_{4}\right)$ will decrease as $A_{4}$ increases in iterative process. Mean while, for $0<\varphi_{3}<\pi / 2$, we have $\cos \left(\varphi_{3}\right)>0$. Then $\gamma_{3}$ will decrease considering $\gamma_{3}=\arctan \left(\frac{\cot \left(\mathrm{a}_{4}\right)}{\cos \left(\varphi_{3}\right)}\right)$.

From the proof of Lemma 2, we can readily have that angle $a_{3}$ will decrease correspondingly in the case $0<\varphi_{2}<$ $\pi / 2,3 \pi / 2<\mathrm{a}_{3}<2 \pi, 3 \pi / 2<\mathrm{a}_{3}+\gamma_{2}<5 \pi / 2$ as independent variable $\mathrm{k}_{2}$ increases.

Considering $\mathrm{b}_{4}=\mathrm{a}_{3}+\angle \mathrm{p}_{3} \mathrm{Op}_{6}$ and $\angle \mathrm{p}_{3} \mathrm{Op}_{6}$ do not change during the iterative process. Thus it is obvious to get as independent variable $\mathrm{k}_{2}$ increases; angle $\mathrm{b}_{4}$ will decrease correspondingly in above case.

Noting $0<\gamma_{3}+b_{4}<\pi / 2$ and angle $b_{4}$ and $\gamma_{3}$ will decreases as independent variable $\mathrm{k}_{2}$ increases in some case, it can be obtained easily that $\sin \left(b_{4}+\gamma_{3}\right)$ will decrease correspondingly with the increase of independent variable $\mathrm{k}_{2}$. Then we have $\mathrm{F}=\sqrt{1-\left(\sin \left(\mathrm{a}_{4}\right)\right)^{2}\left(\sin \left(\varphi_{3}\right)\right)^{2}}\left(\sin \left(\mathrm{b}_{4}+\gamma_{3}\right)\right)$ will decrease.

Thus we can draw the conclusion that cosine of angle between line $L_{1}$ and line $L_{3}$ will decrease as independent variable $\mathrm{k}_{2}$ increases in some case. So, as independent variable $k_{2}$ increase, angle between line $L_{1}$ and line $L_{3}$ will increase correspondingly in the case (1) (2) (3). Q.E.D.

\section{RESULTS AND DISCUSSION}

We do the following instance assumption for the length and angle of visual localization model for space lines intersecting at two points in Fig. 1. Simulation experiments were carried out in the case camera view angle is $36^{\circ} \times 36^{\circ}$. It is assumed that the length of each line segments is $30 \mathrm{~cm}$ for three space lines intersecting at two points. The angel between each two line segments is $60^{\circ}$ in three line segments.

The angle between the first line and third lines is monotone increasing in the geometric space we study in this paper with the increase of distance between initial iteration point and the camera optical center in monocular vision positioning method. Convergence curve is shown in Fig. 7 that iterative solution method converges to the correct answer. The abscissa represents the distance between initial iteration point and camera optical center. The ordinate represents the angle between first line and third line. The solution process finishes when the angle is achieved at and the iterative method converges to the correct solution.

The results are shown in Fig. 8 if we do the analysis for running time of iterative methods in solving geometric space studied in this paper. Fig. 8 shows the average consumption time in each test point for the two solution method. Simulation results show that the iterative method for solving geometric space studied in this paper has faster iterative speed and shorter operation time relative to the iteration method in the reference?

\section{Conclusion}

Numerical solution method is not easy to guarantee the uniqueness of numerical solution method in the optimization

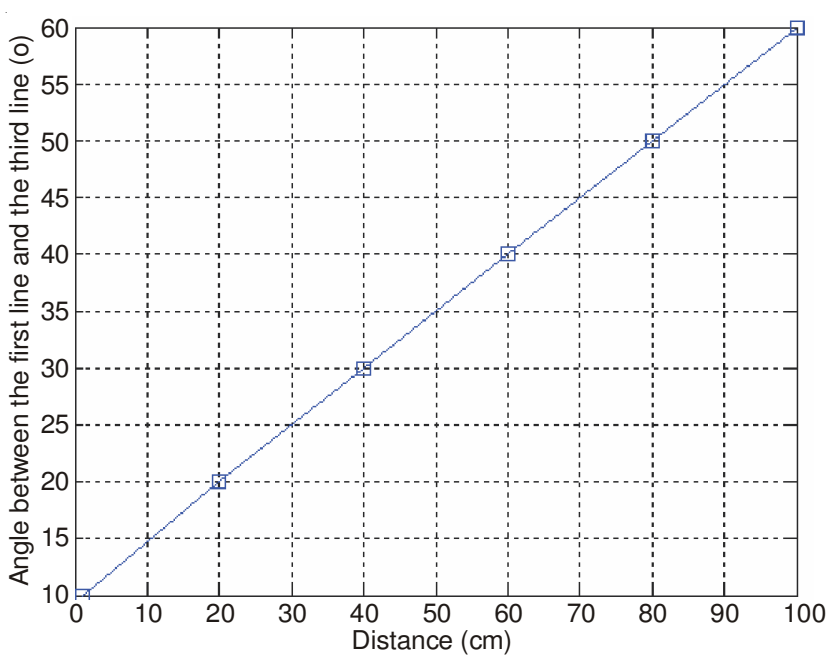

Fig. 7. Convergence diagrammatic sketch of iteration method in solving geometric space

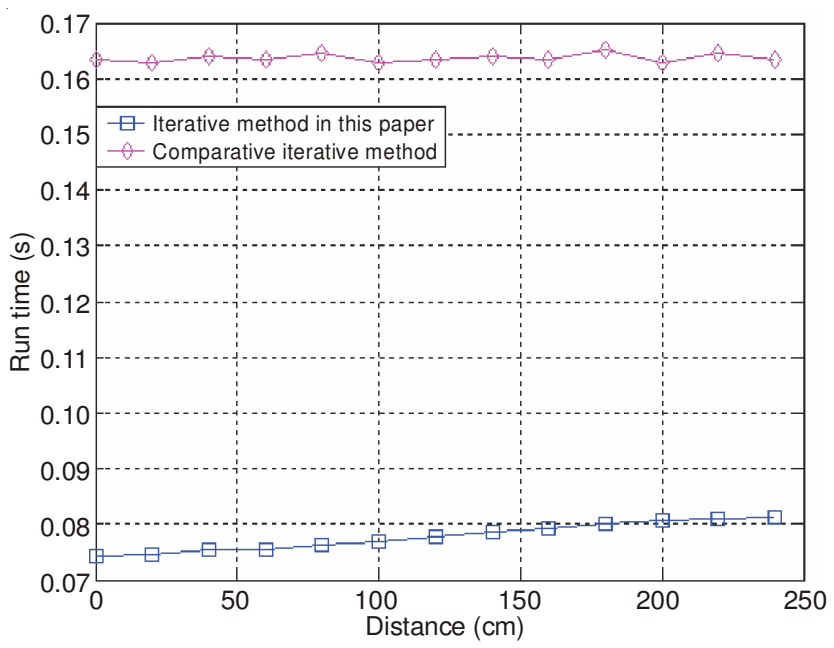

Fig. 8. Comparison picture of running time for iterative methods

process although the visual position has the advantages of high measuring precision. At the same time, the iterative time is long. A new vision iterative method has been proposed based on geometrical meaning and step acceleration method for three space lines intersecting at two points of visual positioning method. This method is fast and easy to guarantee the uniqueness of the solution. It can avoid falling into local minima. The application premise of this method is to satisfy monotonic so as to find the geometric space the solution can satisfy the monotonic and ensure vision measurement method converges to the correct solution. We propose detailed proof process for the monotonic of solution geometric space for iterative method in this paper. The value of research of geometry space is to provide theoretic base for practical application of iterative method and direct the application of visual measurement algorithm.

\section{ACKNOWLEDGEMENTS}

The research work of this paper was supported by National Natural Science Foundation Project of P.R. China (Grant No.61203163). The research work of this paper was supported by Project of State Key Laboratory of Robotics Fund of P.R. China (2013-O06). 


\section{REFERENCES}

1. J.H. Qiu, M.X. Shen, J.H. Cong and L.G. Li, J. Zhejiang Forestry College, 27, 65 (2010).

2. X.Z. Tang, Z.M. Sun and X.L. Jia and D. He, Geogr. Spatial Inform., 10, 100 (2012)

3. Y.X. Han, Z.S. Zhang and M. Dai, Optics Precision Eng., 19, 1110 (2011).

4. S.J. He, Z.Y. Liu and J.Q. Shi, Computer Applications, 32, 2556 (2012).

5. T.Q. Phong, R. Horaud, A. Yassine and P.D. Tao, Int. J. Comput. Vis., 15, 225 (1995).
6. J.S.-C. Yuan, IEEE Trans. Robot. Autom., 5, 129 (1989).

7. Y. Liu, T.S. Huang and O.D. Faugeras, IEEE Trans. Pattern Anal. Mach. Intell., 12, 28 (1990).

8. S. Christy and R. Horaud, Comput. Vis. Image Underst., 73, 137 (1999).

9. L.J. Qin and F. Zhu, IEEE International Conference on Information and Acquirement, p. 26 (2006).

10. L.J. Qin and Y..L. Hu, Adv. Mater. Res., 186, 650 (2011).

11. L.J. Qin, Y.L. Hu, Y.Z. Wei, Y. Zhou and H. Wang, Chinese Control and Decision Conference, pp. 258-263 (2008).

12. L.J. Qin, J. Shenyang Ligong Univ., 32, 1 (2013). 